\title{
Enhanced OLED performance upon photolithographic patterning by using an atomic-layer-deposited buffer layer
}

\author{
Chih-Yu Chang, Feng-Yu Tsai *, Syue-Jhao Jhuo, Miin-Jang Chen \\ Department of Materials Science and Engineering, National Taiwan University, 1, Section 4, Roosevelt Road, Taipei, Taiwan, ROC
}

\section{A R T I C L E I N F O}

\section{Article history:}

Received 9 March 2008

Received in revised form 28 April 2008

Accepted 29 April 2008

Available online 7 May 2008

\section{PACS: \\ 72.80.Le \\ 78.60.Fi \\ 85.60.Jb \\ 81.15.Gh \\ 85.40.Hp}

Keywords:

Atomic layer deposition

Electroluminescence

Photolithography

Conjugated polymer

\begin{abstract}
A B S T R A C T
This study addresses the problem of patterning-induced degradations to organic lightemitting diodes (OLEDs) by using a thin (10 ̊) atomic-layer-deposited ( $\mathrm{ALD}$ ) $\mathrm{Al}_{2} \mathrm{O}_{3}$ film as both an electron-injection layer and a protecting layer for the electroluminescent material, poly[1-methoxy-4-(2'-ethyl-hexyloxy)-2,5-phenylene vinylene] (MEH-PPV). With the $\mathrm{ALD} \mathrm{Al}_{2} \mathrm{O}_{3}$ film, the OLEDs not only withstood an aggressive photolithographic patterning process without any degradation but unprecedentedly showed increased luminous efficiency (by 100\%) and lowered turn-on voltage (by 19\%) afterward. Although the ALD precursor, trimethylaluminum (TMA), was found to damage the MEH-PPV layer through electrophilic addition to the vinylene groups of MEH-PPV during the deposition of the $\mathrm{Al}_{2} \mathrm{O}_{3}$ film, its damaging effect was eliminated by pre-treating the MEH-PPV surface with isopropyl alcohol (IPA), whose hydroxyl groups scavenged TMA throughout the ALD process. The performance of the photo-patterned OLEDs was further improved by using a high-conductivity hole-injection layer, which increased accumulation of holes at the ELbuffer interface to enhance electron injection. The method reported herein improves the applicability of photolithography to OLED fabrication, promising to resolve the issue of patterning that has in part impeded OLED's commercialization.
\end{abstract}

(c) 2008 Elsevier B.V. All rights reserved.

\section{Introduction}

Although organic light-emitting diodes (OLEDs) are finding increasing use in flat panel displays [1-4], their applications in displays are still limited due in part to the lack of an economical yet adequate method for patterning the electroluminescent (EL) materials into fine pixels. Patterning methods currently used for manufacturing or demonstrating OLED displays include evaporation through shadow masks and ink-jet printing [5-7], both of which are relatively slow [8,9], incompatible with many EL materials [10], and limited in pattern resolution [9,11]. Photolithography, the standard patterning method used in the displays industry, would also be ideal for OLEDs, but it has been shown incompatible with OLEDs due to the sus-

\footnotetext{
* Corresponding author. Tel.: +886 2 33665302; fax: +886 223634562. E-mail address: ftsai@ntu.edu.tw (F.-Y. Tsai).
}

ceptibility of the EL materials to the typical solvents or reactive gases used in a photolithographic process $[12,13]$. On the other hand, an OLED device can use a thin insulator layer at the interface between the cathode and the EL layers, such as $\mathrm{MgO}$ [14], $\mathrm{SiO}_{2}$ [15] and $\mathrm{Al}_{2} \mathrm{O}_{3}$ $[16,17]$ to enhance the injection of electrons. The insulator layer, commonly referred to as the buffer layer, operates by reducing the effective barrier for electron injection and by blocking holes from the cathode [18-20], thereby lowering the operating voltage and improving the EL efficiency.

The objective of this study is to develop a photolithographic patterning (photo-patterning) technique for OLEDs that does not compromise the OLED performance. The approach adopted in this study is to use a buffer layer to both protect the EL layer of an OLED device during photo-patterning and to enhance the performance of the patterned device (see Fig. 1 for a schematic drawing of the proposed patterning process). Given that an effective buffer layer 

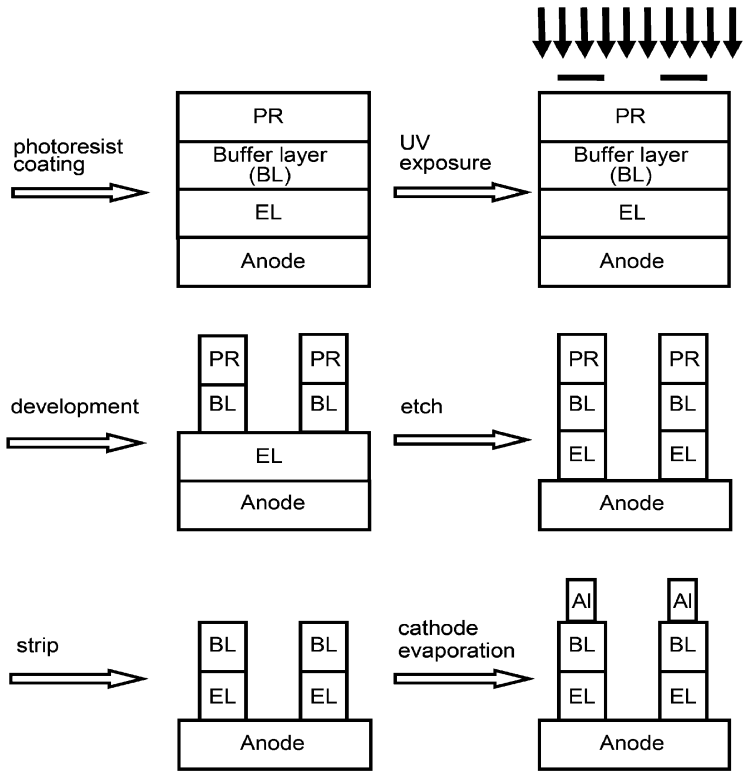

PR: positive-tone photoresist

Fig. 1. Schematic drawings of the buffer-protected patterning process demonstrated in this study.

must be thin, typically in the range of $5-20 \AA[21,22]$, it must have complete and uniform coverage over the EL layer to provide adequate protection throughout the patterning process. We used atomic layer deposition (ALD) to form $\mathrm{Al}_{2} \mathrm{O}_{3}$ films as the buffer layers, taking advantage of ALD's low defect density, high conformality, and low deposition temperatures to maximize the surface coverage of such thin films and to avoid thermally degrading the EL layer [23-25]. The content of this study is as follow: First, the minimum thickness of the $\mathrm{ALD} \mathrm{Al}_{2} \mathrm{O}_{3}$ film required to protect the EL layer was determined by ultrasonicating $\mathrm{Al}_{2} \mathrm{O}_{3}$-coated EL films in a solvent and then inspecting their appearances. Second, the effects of the added $\mathrm{Al}_{2} \mathrm{O}_{3}$ layer on the characteristics of the OLED devices were evaluated, and the ALD process was modified, to ensure that the $\mathrm{Al}_{2} \mathrm{O}_{3}$ layer served as an effective buffer. Third, the OLED characteristics were evaluated again with devices patterned using a typical photolithography process. Finally, methods for further improving the characteristics of the photo-patterned OLEDs were explored.

\section{Experimental}

\subsection{Device fabrication and characterization}

The OLED device used in this study was segmented monochromatic display with poly[1-methoxy-4-(2'-ethylhexyloxy)-2,5-phenylene vinylene] (MEH-PPV) as the EL material. The cross-sectional structure for the control devices was indium tin oxide (ITO)/poly(3,4-ethylenedioxythiophene):poly(styrenesulfonate) (PEDOT:PSS)/MEHPPV/Al. For the experimental devices, an $\mathrm{Al}_{2} \mathrm{O}_{3}$ buffer layer was inserted between the MEH-PPV layer and the Al cathode. The substrates were ITO-coated glass with a sheet resistance of $15 \Omega / \mathrm{sq}$ (purchased from Rite Displays). The substrates were cleaned by ultrasonication by turns in trichloroethylene, acetone, methanol and isopropyl alcohol, followed by rinsing with deionized water and blow-drying with nitrogen. Each of the sonication steps was carrier out at $50{ }^{\circ} \mathrm{C}$ for $15 \mathrm{~min}$. Subsequently, PEDOT:PSS (Baytron $\mathrm{P}$ VP AI 4083, purchased from Bayer AG and used after filtering through a $0.2 \mu \mathrm{m}$ filter) was spin-coated at $1500 \mathrm{rpm}$ onto the substrates. The samples were then transferred into a glove box and baked at $160{ }^{\circ} \mathrm{C}$ for $60 \mathrm{~min}$. MEHPPV $\left(\mathrm{Mn}=70,000-1,00,000 \mathrm{~g} \mathrm{~mol}^{-1}\right.$, purchased from Sigma-Aldrich and used as received) in anhydrous toluene ( $7 \mathrm{mg} \mathrm{ml}^{-1}$ and filtered through a $0.2 \mu \mathrm{m}$ filter) was then spin-coated at $1100 \mathrm{rpm}$ onto the PEDOT:PSS layer and baked at $70{ }^{\circ} \mathrm{C}$ for $30 \mathrm{~min}$. A 250 -nm-thick aluminum film was formed onto the MEH-PPV layer as the cathode by thermal evaporation through a shadow mask at $10^{-6}$ Torr. The devices were then encapsulated with a glass lid using photo-curable epoxy resin as sealant. The current-voltageluminance characteristics of the devices were measured with a Keithley 2400 source meter and a Minolta CS-100 chromameter.

\subsection{Spectral characterization and contact angle measurement}

Ultraviolet-visible (UV-Vis) absorption spectra of MEHPPV films were collected with a Jasco V-570 spectrometer. The MEH-PPV films ( $30 \mathrm{~nm}$ in thickness) were spin-coated at $3000 \mathrm{rpm}$ on glass substrates from a $2 \mathrm{mg} \mathrm{mL}^{-1}$ solution in anhydrous toluene. Infrared spectra were collected with a Thermo Nicolet Nexus 470 Fourier transform infrared (FTIR) spectrometer, with the MEH-PPV films on $\mathrm{KBr}$ tablets. Water contact angles were measured using a RaméHart contact angle goniometer (Model 100), where the sessile drop of 2-3 $\mu \mathrm{l}$ in volume was dispensed with a microsyringe and the contact angle was measured within $30 \mathrm{~s}$ after its formation.

\subsection{Atomic layer deposition}

Atomic layer deposition of $\mathrm{Al}_{2} \mathrm{O}_{3}$ was applied to the MEH-PPV layer using a Cambridge NanoTech Savannah 100 ALD system, with trimethylaluminum (TMA) and $\mathrm{H}_{2} \mathrm{O}$ as the precursors. A typical deposition run consisted of a number of identical cycles, each consisting of the following steps: a $0.02 \mathrm{~s}$ pulse of TMA, a $5 \mathrm{~s}$ purge with $\mathrm{N}_{2}$, a $0.1 \mathrm{~s}$ pulse of $\mathrm{H}_{2} \mathrm{O}$, and another $5 \mathrm{~s}$ purge in $\mathrm{N}_{2}$. We also used cycles with $\mathrm{H}_{2} \mathrm{O}$ pulsed before TMA to study the effect of the precursor sequence. The deposition temperature was $75^{\circ} \mathrm{C}$, the chamber pressure 0.1 Torr, and the $\mathrm{N}_{2}$ flow $20 \mathrm{sccm}$. For the ALD process with the IPA pretreatment, anhydrous IPA was spun onto the MEH-PPV films at $400 \mathrm{rpm}$ for $10 \mathrm{~s}$, followed by the ALD process with TMA pulsed first. A cycle produced $1.2 \AA$ of $\mathrm{Al}_{2} \mathrm{O}_{3}$, as determined using a Dektek Model 3030 profilometer. The evaporated $\mathrm{Al}_{2} \mathrm{O}_{3}$ films tested along with the ALD films were thermally evaporated from an $\mathrm{Al}$ source in high vacuum and then oxidized naturally in the ambient air for $10 \mathrm{~min}$. 


\subsection{Photo-patterning process}

Shipley S1813 positive-tone photoresist was spincoated at $3000 \mathrm{rpm}$ onto the MEH-PPV layer and baked for $120 \mathrm{~s}$ at $90^{\circ} \mathrm{C}$, followed by a $10 \mathrm{~s}$ exposure to a $365 \mathrm{~nm}$ UV light (Hsin Han Electronic R-700) through a photomask. The UV-exposed samples were developed in Shipley MF-319 developer for $30 \mathrm{~s}$, rinsed in anhydrous methanol for $1 \mathrm{~min}$, and then dried at $80^{\circ} \mathrm{C}$ for $120 \mathrm{~s}$. The $\mathrm{Al}_{2} \mathrm{O}_{3}$ buffer on the UV-exposed area was dissolved in the developer as well, and its underlying MEH-PPV was subsequently wet-etched with anhydrous toluene (120 s). After the etch step, the photoresist was stripped by sonication in anhydrous acetone for $120 \mathrm{~s}$, and then dried at $100^{\circ} \mathrm{C}$ for $30 \mathrm{~min}$.

\section{Results and discussion}

To preliminarily verify the surface coverage of the ALD buffer layer over the MEH-PPV layer, several MEH-PPV film samples were overcoated with an ALD $\mathrm{Al}_{2} \mathrm{O}_{3}$ layer of various thicknesses, immersed in toluene for $10 \mathrm{~min}$, and then visually inspected. The ALD layers with thicknesses $\geqslant 10 \AA$ kept the MEH-PPV samples intact; in contrast, an MEH-PPV sample overcoated with a $12 \AA$ evaporated $\mathrm{Al}_{2} \mathrm{O}_{3}$ film, which was tested as a reference along with the ALD-coated samples, completely disintegrated upon the immersion in toluene. This result suggests that the excellent surface coverage of ALD would allow $\mathrm{Al}_{2} \mathrm{O}_{3}$ films with $\geqslant 10 \AA$ thickness to protect an underlying MEH-PPV film through the solution-based photo-patterning process.

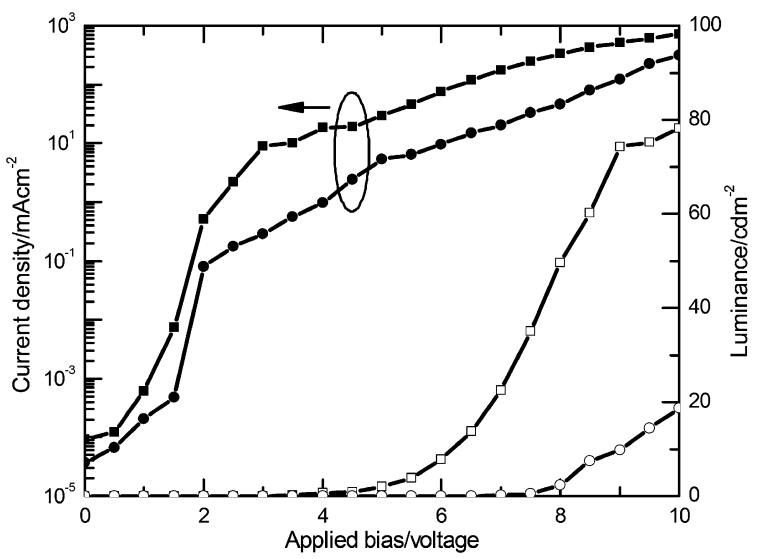

Fig. 2. Current density and luminance vs. applied bias for OLED devices: without the ALD buffer (squares), and with the ALD buffer (circles).
Despite the $\mathrm{ALD} \mathrm{Al}_{2} \mathrm{O}_{3}$ films' confirmed surface coverage, they failed to show the expected benefits of a buffer layer: the devices with a $10-\AA \mathrm{ALD}^{2} \mathrm{O}_{2} \mathrm{O}_{3}$ layer overcoated on the MEH-PPV layer had significantly higher turn-on voltage, lower luminance, and lower luminous efficiency than the control (see Fig. 2 and Table 1). It should be noted that control's low luminance and low luminous efficiency are intrinsic to the device structure (ITO/PEDOT:PSS/ $\mathrm{MEH}-\mathrm{PPV} / \mathrm{Al}$ ), and they are comparable to the optimal device characteristics reported by other researchers for the same device structure [26-28]. The adverse effects of the ALD $\mathrm{Al}_{2} \mathrm{O}_{3}$ layer are attributed to its disrupting the conjugation of MEH-PPV, which is evidenced by the blue shift and the weakened absorption occurring in the UV-Vis spectrum of MEH-PPV upon the application of the ALD $\mathrm{Al}_{2} \mathrm{O}_{3}$ layer (see Fig. 3). The affected MEH-PPV became insulating due to the disrupted conjugation, and therefore the device characteristics deteriorated drastically. By analyzing the UV-Vis spectra (Fig. 3) of MEH-PPV samples processed with different ALD conditions, we determined that exposure to TMA was the sole cause of the disruption of conjugation. As can be seen in Fig. 3, the MEH-PPV sample exposed only to TMA showed identical degradation in its UV-Vis spectrum to that of the $\mathrm{Al}_{2} \mathrm{O}_{3}$-coated sample (which was exposed to both TMA and $\mathrm{H}_{2} \mathrm{O}$ ), while the MEH-PPV sample exposed only to $\mathrm{H}_{2} \mathrm{O}$ did not show detectable change in its UV-Vis spectrum. The significant change in the UV-Vis spectrum caused by the ALD $\mathrm{Al}_{2} \mathrm{O}_{3}$ layer indicates that the TMA exposure affected not only the top surface but also the bulk of the MEH-PPV layer.

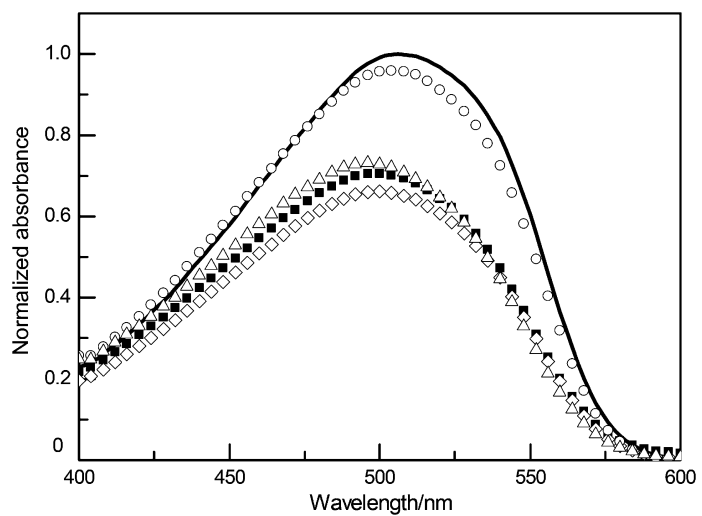

Fig. 3. UV-Vis absorption spectra of MEH-PPV films: pristine (solid lines), with a $10 \AA \mathrm{ALD} \mathrm{Al}_{2} \mathrm{O}_{3}$ film deposited with TMA first (filled squares), with a $10 \AA$ ALD $\mathrm{Al}_{2} \mathrm{O}_{3}$ film deposited with $\mathrm{H}_{2} \mathrm{O}$ first (unfilled triangles), exposed only to $\mathrm{H}_{2} \mathrm{O}$ (unfilled circles), and exposed only to TMA (unfilled diamonds).

Table 1

Characteristics of the OLED devices

\begin{tabular}{llll}
\hline Device & Turn-on voltage $(\mathrm{V})$ & Maximum luminance $\left(\mathrm{cd} / \mathrm{m}^{2}\right)$ \\
\hline No buffer, not patterned & 4.8 & 78 & 19 \\
With ALD buffer, not patterned & 7.7 & 242 & $1.4 \times 10^{-2}$ \\
With IPA-pretreated ALD buffer, not patterned & 3.0 & $9.3 \times 10^{-3}$ \\
With IPA-pretreated ALD buffer, patterned & 3.9 & 217 & $3.0 \times 10^{-2}$ \\
With IPA-pretreated ALD buffer and & 2.8 & 322 & $2.8 \times 10^{-2}$ \\
$\quad$ high-conductivity PEDOT:PSS, patterned & & & $4.2 \times 10^{-2}$ \\
\hline
\end{tabular}




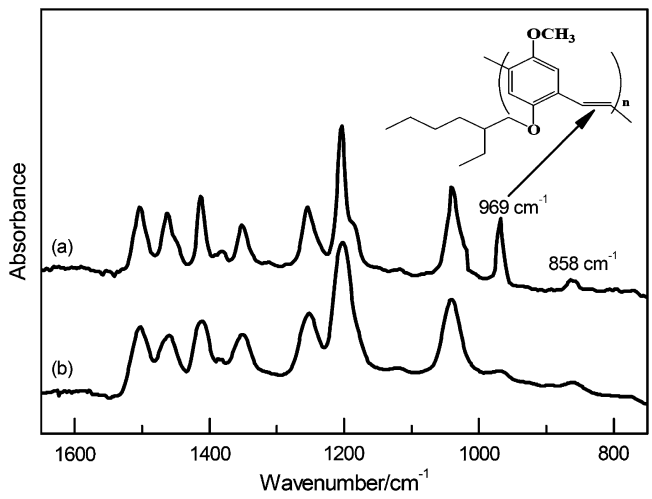

Fig. 4. IR spectra of MEH-PPV films: (a) pristine (b) TMA-exposed (150 consecutive $0.02-\mathrm{s}$ pulses). The peak at $969 \mathrm{~cm}^{-1}$ corresponds to the vinylene double bonds of MEH-PPV, as illustrated in the margin.

This was to be expected from the elevated temperature used in the ALD process, which accelerated the permeation of TMA vapors into the MEH-PPV layer.

We further determined that the mechanism of the conjugation disruption is through electrophilic addition of TMA to the vinylene $\mathrm{C}=\mathrm{C}$ groups of MEH-PPV, which can be seen by comparing the FTIR spectra shown in Fig. 4 of an MEH-PPV film before and after TMA exposure: The TMA-exposed spectrum showed significantly weakened vinylene absorption band $\left(969 \mathrm{~cm}^{-1}\right)$. This mechanism is consistent with the fact that TMA, being a strong Lewis acid, has high reactivity for electrophilic addition to unsaturated bonds. The TMA exposure also created a new FTIR spectral feature at $\sim 860 \mathrm{~cm}^{-1}$ corresponding to the Al-O bond, which was formed by oxidation of the added TMA by $\mathrm{O}_{2}$ or $\mathrm{H}_{2} \mathrm{O}$ upon the sample's exposure to air [29]. It should be noted that the significant change in the FTIR spectra upon the TMA exposure indicates again the deep penetration of the TMA vapors into the MEH-PPV layer.

The TMA attack on the MEH-PPV layer was reduced, but not eliminated, by introducing $\mathrm{H}_{2} \mathrm{O}$ before TMA in the ALD cycles, as can be seen from the smaller blue shift and less weakening of the UV-Vis spectrum produced by the $\mathrm{H}_{2} \mathrm{O}$ first process than that of the regular TMA-first process (see Fig. 3). The $\mathrm{H}_{2} \mathrm{O}$-first process impeded the TMA attack by initially providing to the MEH-PPV surface a layer of adsorbed $\mathrm{H}_{2} \mathrm{O}$ molecules, which shielded the MEH-PPV layer from TMA in the subsequent process. However, the shielding effect of the $\mathrm{H}_{2} \mathrm{O}$-first process was modest due to the hydrophobicity of the MEH-PPV surface, which limited the amount of the initially adsorbed $\mathrm{H}_{2} \mathrm{O}$ molecules.

The problem of incomplete shielding of the $\mathrm{H}_{2} \mathrm{O}$-first process was resolved by pre-treating the MEH-PPV surface with isopropyl alcohol (IPA) immediately before the ALD process. The hydrophobic alkyl groups of IPA ensured its full adsorption onto the also hydrophobic MEH-PPV surface, while its hydroxyl groups served as reactive sites for capturing TMA during the ALD process, as illustrated in Fig. 5. The mechanism proposed in Fig. 5 agrees with the results of contact angle measurements on the MEH-PPV surface (see Fig. 6): the water contact angle reduced from $87^{\circ}$ to $50^{\circ}$ upon the IPA pretreatment, indicating that IPA effectively converted the hydrophobic MEH-PPV surface into a hydrophilic one. The IPA pretreatment completely prevented the TMA-induced damages, allowing ALD-processed MEH-PPV films to show identical UV-Vis spectra to that of the pristine film (Note: spectra of the IPA-pretreated, ALD-processed MEH-PPV samples was indistinguishable from that of the pristine sample and are not shown.). Furthermore, OLED devices with a 10-Å IPA-pretreated $\mathrm{ALD} \mathrm{Al}_{2} \mathrm{O}_{3}$ buffer layer indeed showed the expected benefits of the buffer layer, i.e., decreased turn-on voltage and increased efficiency compared with the devices without the $\mathrm{Al}_{2} \mathrm{O}_{3}$ buffer (see Fig. 7 and Table 1 ).

The 10- $\AA$ IPA-pretreated $\mathrm{ALD} \mathrm{Al}_{2} \mathrm{O}_{3}$ buffer layer was also effective in protecting MEH-PPV films through the photopatterning process, as evidenced by the identical UV-Vis
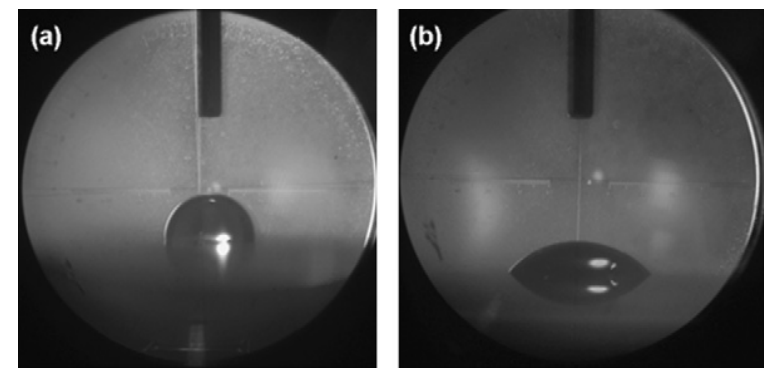

Fig. 6. Images from water contact angle measurements on MEH-PPV surface: (a) pristine (contact angle $=87^{\circ}$ ), and (b) IPA-pretreated (contact angle $=50^{\circ}$ ).

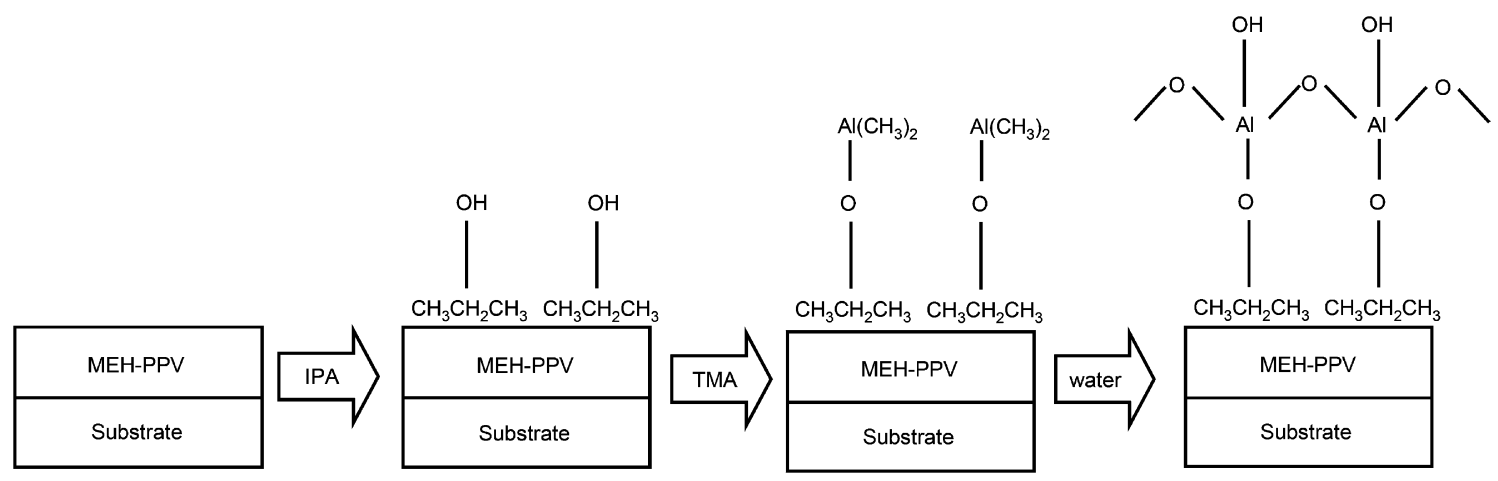

Fig. 5. Schematic drawings of the IPA-pretreated ALD process. 
a

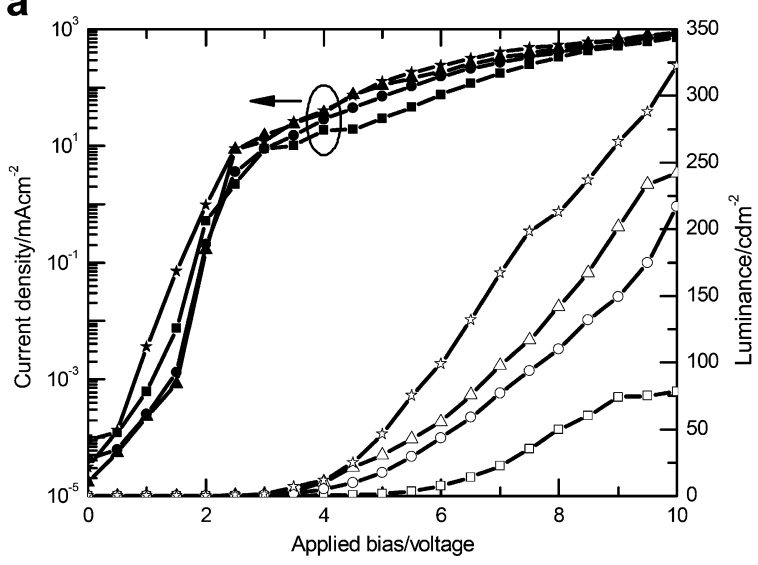

b

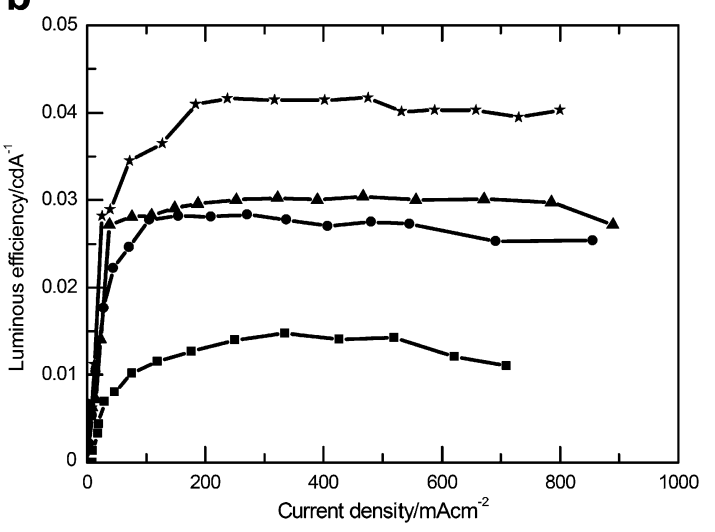

Fig. 7. (a) Current density and luminance vs. applied bias, (b) luminous efficiency vs. current density for the OLED devices: without the ALD buffer and not patterned (squares); with the ALD buffer and patterned (circles); with the ALD buffer but not patterned (triangles), and with the ALD buffer and high-conductivity PEDOT:PSS and patterned (stars). Note that the ALD buffer was deposited with the IPA pretreatment.

spectra of the photo-patterned MEH-PPV films to that of the pristine film (Note: the patterned spectra were indistinguishable from the pristine and are not shown.). More important, the OLED devices fabricated with the photopatterned, ALD-coated MEH-PPV films showed higher luminous efficiency and lower turn-on voltage than the control devices which were not photo-patterned and without the buffer (Fig. 7 and Table 1). The above results confirm that the ALD-buffer-assisted photo-patterning process is capable of both patterning and improving OLED devices. It should be noted that the photo-patterning process did compromise part of the improvement yielded by the ALD buffer, but the net effect was still positive (Fig. 7 and Table 1).

The EL efficiency could be further improved (by 50\%) and turn-on voltage further lowered (by $28 \%$ ) by increasing the conductivity of the hole injection layer (HIL), PEDOT:PSS, as shown in Fig. 7 and Table 1. The conductivity of the HIL was increased by $\sim 2$ orders of magnitude by adding $5 \mathrm{wt} . \%$ of glycerol into the PEDOT:PSS solution [30]. The mechanism of this further improvement is explained as follow. In hole-dominated OLEDs such as the
MEH-PPV-based devices studied here, a large portion of holes reach the cathode without participating in radiative recombination with electrons, thus resulting in loss of luminous efficiency. When an insulating buffer is used, holes are prevented from quenching at the cathode, and they in turn accumulate at the EL-buffer interface. The accumulated holes create interfacial dipoles that enhance electron injection from the cathode by lowering the injection barrier, while their proximity to the cathode enables them to readily capture and recombine with the injected electrons; consequently, the turn-on voltage is lowered and the EL efficiency is improved [31-33]. Increasing the conductivity of the HIL increases the accumulation of holes at the EL-buffer interface, thereby strengthening the benefits of the insulating buffer layer. We expect that more improvement can be realized with HIL with even higher conductivity, which is the subject of our on-going effort.

\section{Conclusion}

We demonstrated a practical solution to the heretofore unavoidable problem of patterning-induced degradations for OLEDs. OLEDs with MEH-PPV as the EL material were photo-patterned without degradation by using an ultrathin (10 $\AA$ ) ALD $\mathrm{Al}_{2} \mathrm{O}_{3}$ film overcoated on the EL layer to protect against damages induced by the solution-based photo-patterning process. Besides providing protections, the $\mathrm{Al}_{2} \mathrm{O}_{3}$ film served as an effective buffer layer to improve luminous efficiency (by 100\%) and to lower turnon voltage (by 19\%) of the photo-patterned OLEDs. Although the ALD precursor, TMA, disrupted the conjugation of MEH-PPV by electrophilic addition to its vinylene moiety during the deposition of the $\mathrm{Al}_{2} \mathrm{O}_{3}$ film, this reaction was prevented by pretreating the MEH-PPV layer with IPA immediately before the ALD process, where the pre-adsorbed IPA molecules reacted with TMA to shield the underlying MEH-PPV surface. The device characteristics of the photo-patterned OLEDs were further improved by increasing the conductivity of the HIL, which increased hole accumulation at the EL-buffer interface to enhance electron injection.

\section{Acknowledgement}

This work was supported by National Science Council of Taiwan, Republic of China, under Grant No. NSC 96-2221E-002-143-MY3.

\section{Appendix A. Supplementary material}

Supplementary data associated with this article can be found, in the online version, at doi:10.1016/ j.orgel.2008.04.009.

\section{References}

[1] W. Tang, S.A. VanSlyke, Appl. Phys. Lett. 51 (1987) 913.

[2] R.H. Friend, R.W. Gymer, A.B. Holmes, J.H. Burroughes, R.N. Marks, C. Taliani, D.D.C. Bradley, D.A. Dos Santos, J.L. Brédas, M. Lögdlund, W.R. Salaneck, Nature 397 (1999) 121. 
[3] D. Vak, J. Jo, J. Ghim, C. Chun, B. Lim, A.J. Heeger, D.Y. Kim, Macromolecules 39 (2006) 6433.

[4] M.T. Bernius, M. Inbasekaran, J. O’Brien, W. Wu, Adv. Mater. 12 (2000) 1737.

[5] P.F. Tian, V. Bulovic, P.E. Burrows, G. Gu, S.R. Forrest, T.X. Zhou, J. Vac. Sci. Technol. A 17 (1997) 3197.

[6] T.R. Hebner, C.C. Wu, D. Marcy, M.H. Lu, J.C. Sturn, Appl. Phys. Lett 72 (1998) 519.

[7] D.B. Roitman, US Patent, 5,972,419, 1999.

[8] J.A. DeFranco, B.S. Schmidt, M. Lipson, G.G. Malliaras, Org. Electron. 7 (2006) 22.

[9] J. Huang, R. Xia, Y. Kim, X. Wang, J. Dane, O. Hofmann, A. Mosley, A.J. de Mello, J.C. de Mello, D.D.C. Bradley, J. Mater. Chem. 17 (2007) 1043.

[10] S.-C. Chang, J. Bharathan, Y. Yang, R. Helgeson, F. Wudl, M.B. Ramey, J.R. Reynolds, Appl. Phys. Lett. 73 (1998) 2561

[11] Y. Yang, S.-C. Chang, J. Bharathan, J. Liu, J. Mater. Sci.: Mater. Electron. 11 (2000) 89.

[12] P.F. Tian, P.E. Burrows, S.R. Forrest, Appl. Phys. Lett. 71 (1997) 3197.

[13] D.G. Lidzey, M.A. Pate, M.S. Weaver, T.A. Fisher, D.D.C. Bradley, Synth. Met. 82 (1996) 141

[14] H.W. Choi, S.Y. Kim, W.K. Kim, J.L. Lee, Appl. Phys. Lett. 87 (2005) 082102.

[15] Z.B. Deng, X.M. Ding, S.T. Lee, W.A. Gambling, Appl. Phys. Lett. 74 (1999) 2227.

[16] F. Li, H. Tang, J. Anderegg, J. Shinar, Appl. Phys. Lett. 70 (1997) 1233.

[17] H. Tang, F. Li, J. Shinar, Appl. Phys. Lett 71 (1997) 2560.

[18] J.H. Park, O.O. Park, J.W. Yu, J.K. Kim, Y.C. Kim, Appl. Phys. Lett. 84 (2004) 1783.
[19] T.M. Brown, R.H. Friend, I.S. Millard, D.J. Lacey, T. Butler, J.H. Burroughes, F. Cacialli, J. Appl. Phys. 93 (2003) 6159.

[20] T.-F. Guo, F.-S. Yang, Z.-J. Tsai, T.-C. Wen, S.-N. Hsieh, Y.-S. Fu, C.-T. Chung, Appl. Phys. Lett. 88 (2006) 113501

[21] U. Wolf, H. Bässler, Appl. Phys. Lett. 74 (1999) 3848.

[22] S.T. Zhang, X.M. Ding, J.M. Zhao, H.Z. Shi, J. He, Z.H. Xiong, H.J. Ding, E.G. Obbard, Y.Q. Zhan, W. Huang, X.Y. Hou, Appl. Phys. Lett. 84 (2004) 425.

[23] M. Ritala, M. Leskelä, in: H.S. Nalwa (Ed.), Handbook of Thin Film Materials, vol. 1, Academic Press, San Diego, 2002. (Chapter 2).

[24] R.L. Puurunen, J. Appl. Phys. 97 (2005) 121301.

[25] M.D. Groner, F.H. Fabreguette, J.W. Elam, S.M. George, Chem. Mater. $16(2004) 639$.

[26] C.J. Tonzola, M.M. Alam, W. Kaminsky, S.A. Jenekhe, J. Am. Chem. Soc 125 (2003) 13548

[27] R. Yang, H. Wu, Y. Cao, G.C. Bazan, J. Am. Chem. Soc. 128 (2006) 14422.

[28] S.-H. Jin, S.-Y. Kang, M.-Y. Kim, Y.U. Chan, J.Y. Kim, K. Lee, Y.-S. Gal, Macromolecules 36 (2003) 3841.

[29] M.M. Frank, Y.J. Chabal, M.L. Green, A. Delabie, B. Brijs, G.D. Wilk, M.Y. Ho, E.B.O. da Rosa, I.J.R. Baumvol, F.C. Stedile, Appl. Phys. Lett. 83 (2003) 740.

[30] J. Huang, P.F. Miller, J.S. Wilson, A.J. de Mello, J.C. de Mello, D.D.C. Bradley, Adv. Funct. Mater. 15 (2005) 290.

[31] Y.E. Kim, H. Park, J.J. Kim, Appl. Phys. Lett. 69 (1996) 599.

[32] S.T. Zhang, Y.C. Zhou, J.M. Zhao, Y.Q. Zhan, Z.J. Wang, Y. Wu, X.M. Ding, X.Y. Hou, Appl. Phys. Lett. 89 (2006) 043502.

[33] Y.-H. Niu, H. Ma, Q. Xu, A.K.-Y. Jen, Appl. Phys. Lett. 86 (2005) 083504. 